\title{
Seleção simultânea de Coffea canephora por meio da combinação de análise de fatores e índices de seleção
}

\author{
Adésio Ferreira ${ }^{(1)}$, Paulo Roberto Cecon ${ }^{(1)}$, Cosme Damião Cruz $^{(1)}$, Romário Gava Ferrão(2), \\ Marcia Flores da Silva( ${ }^{(1)}$, Aymbiré Francisco Almeida da Fonseca(3) e Maria Amélia Gava Ferrão(3)
}

\begin{abstract}
(1)Universidade Federal de Viçosa, Avenida P. H. Rolfs, s/no, CEP 36570-000 Viçosa, MG. E-mail: adesio@vicosa.ufv.br, cecon@dpi.ufv.br, cdcruz@ufv.br, mfloress@vicosa.ufv.br (2)Instituto Capixaba de Pesquisa, Assistência Técnica e Extensão Rural (Incaper), Rua Afonso Sarlo, no 160, Bento Ferreira, CEP 29052-010 Vitória, ES. E-mail: romario@incaper.es.gov.br (3)Incaper, Centro Regional de Desenvolvimento Rural Centro-Serrano, BR 262, Km 92, CEP 29375-000 Venda Nova do Imigrante, ES. E-mail: aymbire@incaper.es.gov.br, mferrao@incaper.es.gov.br
\end{abstract}

\begin{abstract}
Resumo - O objetivo deste trabalho foi avaliar a possibilidade do emprego de índices de seleção em complexos fatoriais, de modo a auxiliar na seleção simultânea de caracteres de Coffea canephora var. Conilon, na predição de ganhos por seleção. Foram analisados e avaliados quatorze características e 40 genótipos de dois experimentos, pertencentes ao programa de melhoramento genético de café ‘Conilon’ do Incaper, Marilândia, ES, e em Sooretama, ES. Os experimentos foram instalados em delineamento de blocos ao acaso, com quatro repetições e duas plantas úteis por parcela. $\mathrm{O}$ uso dos complexos fatoriais eliminou o problema da multicolinearidade e permitiu a adequada utilização da teoria de índice de seleção, para melhoramento simultâneo de caracteres. Foram utilizados os índices de seleção de Smith e Hazel e de Pesek \& Baker, e o primeiro foi a melhor alternativa na obtenção de ganhos simultâneos adequados. A utilização conjunta das técnicas multivariadas de análise de fatores, para simplificação estrutural prévia no número de caracteres, e de índices de seleção na predição de ganhos simultâneos são alternativas eficientes no melhoramento genético da cultura.
\end{abstract}

Termos para indexação: café, melhoramento vegetal, ganhos por seleção, análise multivariada.

\section{Simultaneous selection of Coffea canephora by means of combination of factor analysis and selection indexes}

\begin{abstract}
The objective of this work was to evaluate the possibility of using selection indexes in factorial complexes, in the simultaneous selection of characters of Coffea canephora (Conilon var.), when predicting the selection gains. Fourteen characters and 40 genotypes were analyzed in two experiments of the genetic improvement program of 'Conilon' coffee, developed by Incaper, carried out in Marilândia and Sooretama, ES, Brazil. The experiments were conducted on a randomized block design, with four replicates and two useful plants in each plot. Factorial complexes eliminated the multicolinearity problem, allowing the appropriate use of the selection index theory for simultaneous improvements of characters. The selection indexes by Smith and Hazel and Pesek \& Baker were used, and the first one was the best alternative to obtain adequate simultaneous gains. The combined use of multivariate techniques of the factor analysis, for previous structural simplification in the number of characters, and selection indexes to predict simultaneous gains are efficient alternatives in the coffee cropping genetic improvement.
\end{abstract}

Index terms: coffee, plant breeding, selection gains, multivariate analysis.

\section{Introdução}

A cultura do café teve grande influência na colonização e no desenvolvimento do Brasil e, atualmente, continua ocupando posição de destaque no cenário econômico e social do país, que é o maior produtor e exportador de café no mundo, além de se destacar também como o segundo maior consumidor (Fonseca, 1999).
Na produção mundial de café, duas espécies, C. canephora e C. arabica, representam quase a totalidade comercializada. A C. canephora só começou a ser explorada, de modo expressivo, no Brasil, a partir de 1960, principalmente no Estado do Espírito Santo (Matiello \& Almeida, 1997), e tem despertado grande interesse, entre os melhoristas, por seu alto potencial produtivo, grande rusticidade e maior quantidade de sólidos 
solúveis totais, em comparação à $C$. arabica. Essas características tornam a espécie muito desejada pelas indústrias e estimula a adoção de estratégias de melhoramento, baseadas na transferência de genes para outras espécies.

Segundo Charrier \& Berthaud (1988), os programas de melhoramento de $C$. canephora ambicionam a melhoria de várias características, prioritariamente, a produtividade, a estabilidade de produção em diferentes ambientes e a qualidade da produção. Características do fruto, tais como: uniformidade de maturação, aumento do tamanho dos grãos, conversão entre café cereja e beneficiado, teor de sólidos solúveis totais, redução da porcentagem de grãos mocas e teor de cafeína, também devem ser consideradas. Quanto às características gerais das plantas, geralmente, são selecionadas as de porte mais baixo e arquitetura mais compacta, adequadas ao adensamento e com maior tolerância às principais doenças, às pragas, e à seca. A seleção de um conjunto de caracteres de importância é necessária, visando ganhos adequados, simultaneamente, em todas as características nos programas de melhoramento. Assim, de acordo com Cruz \& Regazzi (2001), a utilização de índice de seleção, estabelecida pela combinação ótima de vários caracteres, é uma técnica biométrica que permite efetuar, com eficiência, a seleção simultânea de caracteres múltiplos.

Quando se dispõe de grande número de características a serem consideradas no processo seletivo, é possível a ocorrência de multicolinearidade, que invalida o uso da teoria convencional de índice de seleção, como proposta por Smith (1936) e Hazel (1943). Diz-se haver inter-relação ou multicolinearidade, quando as variáveis analisadas apresentam certo grau de correlação entre si. A ocorrência de grau de multicolinearidade severa pode ocasionar resultados prejudiciais e absurdos em muitos procedimentos biométricos, que se fundamentam em inversões de matrizes de covariâncias e, no caso de índices de seleção, pode proporcionar valores de coeficiente de ponderação dos caracteres em índices pouco confiáveis e, portanto, inadequados para uso no melhoramento (Cruz \& Carneiro, 2003).

No melhoramento do cafeeiro, em que várias características são consideradas, elevados graus de correlação são observados. Assim, a técnica de análise de fatores pode ser uma solução biométrica, para viabilizar o uso de índice de seleção, sem a necessidade de exclusão de variáveis ou adoção de técnica alternativa de estimação, como preconizado por Carvalho (1995), que observa que a aplicação de seleção simultânea, baseada em índice de seleção, requer o diagnóstico de multicolinearidade na matriz de correlação, entre os dados de todas as características sob seleção.
Recomenda-se reunir, previamente, as características mais correlacionadas em complexos de interpretação biológica e, depois da simplificação estrutural, submeter essas novas características à análise por índice de seleção. A teoria de simplificação estrutural, conhecida no campo da estatística multivariada como análise de fatores, é de ampla aplicação entre os melhoristas e a sua utilização pelo modelo de fatores ortogonais, ou seja, não correlacionados, constitui um meio de eliminar o problema de multicolinearidade e, aliada à teoria de índice de seleção, de obter ganhos simultâneos em várias características.

Este trabalho teve por objetivo avaliar o uso de índices de seleção, em complexos fatoriais, como técnica no auxílio do problema da seleção simultânea de caracteres, em programas de melhoramento de C. canephora var. Conilon, na predição de ganhos por seleção.

\section{Material e Métodos}

Foram estudados 40 genótipos de $C$. canephora var. Conilon, pertencentes ao programa de melhoramento do Incaper, ES, dos quais: 35 clones, originários da seleção fenotípica de plantas matrizes de propriedades agrícolas, em diversos municípios da região norte do Estado; três clones elites, o ES 01, classificado como de maturação precoce, o ES 23, maturação intermediária, e o ES 36, tardio; uma cultivar do tipo população propagada por semente, do programa de melhoramento do Incaper e uma cultivar policlonal comercial.

Foram analisados dados de dois experimentos, provenientes das safras de 1996, 1998, 1999, 2000 e 2001, conduzidos em fazendas experimentais do Incaper, ES, nos Municípios de Marilândia e Sooretama, locais representativos de clima e solo, em que a espécie é cultivada intensivamente, no norte do Estado.

O Município de Marilândia localiza-se a $19^{\circ} 24^{\prime}$ S; $40^{\circ} 31^{\prime} \mathrm{W}$. Sua altitude é de $150 \mathrm{~m}$ e o solo foi classificado como Latossolo Vermelho-Amarelo distrófico arenoso (80\% areia) de baixa fertilidade. Apresenta precipitação pluvial anual de $1.200 \mathrm{~mm}$, temperatura média anual de $23^{\circ} \mathrm{C}$, umidade relativa de $80 \%$ e topografia ondulado-acidentada. O Município de Sooretama localiza-se a $15^{\circ} 47^{\prime} \mathrm{S}$ e $43^{\circ} 18^{\prime} \mathrm{W}$. Altitude é de $40 \mathrm{~m}$ e o solo tem a mesma classificação e fertilidade de Marilândia; a precipitação pluvial anual é de $1.100 \mathrm{~mm}$; a temperatura média anual é $24^{\circ} \mathrm{C}$; e umidade relativa de $80 \%$. Possui uma topografia plana, com vento sul predominante.

A adubação foi realizada de acordo com a análise de solo e com produtividade desejada de 80 sacas beneficiadas por hectare. Foram aplicados $340 \mathrm{~kg} \mathrm{ha}^{-1}$ de $\mathrm{N}$, 
$55 \mathrm{~kg} \mathrm{ha}^{-1}$ de $\mathrm{P}_{2} \mathrm{O}_{5}$ e $170 \mathrm{~kg} \mathrm{ha}^{-1}$ de $\mathrm{K}_{2} \mathrm{O}$, distribuídos em três aplicações. O manejo, a condução e os tratos culturais, nos experimentos, foram realizados de acordo com as necessidades e as recomendações técnicas para a cultura. Os experimentos não foram irrigados.

Os experimentos foram instalados em delineamento experimental de blocos ao acaso, com quatro repetições, e cada parcela foi composta por duas plantas úteis. Foi utilizado o espaçamento de $3 \times 1,5 \mathrm{~m}$, com densidade de plantio de 2.222 plantas ha-1.

Os tratamentos foram avaliados em cinco amostragens aos 24, 48, 60, 72 e 84 meses depois do plantio. As 14 características avaliadas foram: ciclo, que é o número de dias do florescimento principal à colheita; produtividade, que é a produção de grãos beneficiados em $\mathrm{kg} \mathrm{ha}^{-1}$, com 14\% de umidade; rendimento em quilograma de frutos cereja/frutos coco (CeCo); rendimento em quilograma de frutos cereja/grãos beneficiados (CeBe); rendimento em quilograma de fruto coco/grãos beneficiados (CoBe); porcentual de frutos com grãos chochos; porcentual de grãos chatos; porcentual de grãos moca; porcentual de umidade; porcentual de grãos retidos em peneira superior a 15 (Pen.17); porcentual de grãos retidos em peneira 15 (Pen.15); porcentual de grãos retidos em peneira 13 (Pen.13); porcentual de grãos retidos em peneira 11 (Pen.11) e porcentual de grãos retidos em peneira média (PM).

O conjunto de caracteres avaliados foi reunido em grupos, pela técnica multivariada de análise de fatores, conforme Cruz \& Carneiro (2003), tendo resultado em quatro complexos (ou fatores comuns), em Marilândia, e três complexos em Sooretama. O modelo de análise de fatores utilizado foi:

$\mathrm{X}_{\mathrm{j}}=\mathrm{I}_{\mathrm{j} 1} \mathrm{~F}_{1}+\mathrm{I}_{\mathrm{j} 2} \mathrm{~F}_{2+\ldots+} \mathrm{l}_{\mathrm{jm}} \mathrm{F}_{\mathrm{m}}+\varepsilon_{\mathrm{j}}$, em que $\mathrm{X}_{\mathrm{j}}$ é a j-ésima característica avaliada, com $\mathrm{j}=1$, $2, \ldots v ; I_{j k}$ é a carga fatorial para a j-ésima variável, associada ao k-ésimo fator, em que $\mathrm{k}=1,2, \ldots \mathrm{m} ; \mathrm{F}_{\mathrm{k}}$ é o k-ésimo fator comum e $\varepsilon_{\mathrm{j}}$ é o fator específico.

Os índices de seleção utilizados no trabalho foram o índice clássico (Smith, 1936; Hazel, 1943) e o baseado em ganhos desejados (Pesek \& Baker, 1969). O primeiro consiste numa combinação linear dos valores fenotípicos dos vários caracteres de importância econômica, cujos coeficientes de ponderação são estimados de modo a maximizar a correlação entre o índice de seleção e o agregado genotípico. Esse agregado genotípico é estabelecido por uma outra combinação linear, que envolve os valores genéticos, ponderados por seus respectivos valores econômicos. Portanto, na estimação do índice de seleção de cada família ou progênie, é necessária a estimação do vetor b. Esse vetor b é obtido de forma que a correlação entre I e H seja maximizada. Assim, tem-se: $\mathrm{b}=\mathrm{P}^{-1} \mathrm{Ga}$, em que $\mathrm{b}$ é o estimador do vetor de dimensão $\mathrm{n} \times 1$, dos coeficientes de ponderação do índice de seleção; $\mathrm{P}^{-1}$ é a inversa da matriz, de dimensão $\mathrm{n}$ x n, de variâncias e covariâncias fenotípicas entre os caracteres; $\mathrm{G}$ é a matriz, de dimensão $\mathrm{n}$ x n, de variâncias e covariâncias genéticas entre os caracteres; a é o vetor de pesos econômicos.

O ganho esperado para o caráter j, quando a seleção é praticada sobre o índice, é expresso por $\Delta \mathrm{g}_{\mathrm{j}(\mathrm{I})}=\mathrm{DS}_{\mathrm{j}(\mathrm{I})} \mathrm{h}_{\mathrm{j}}^{2}$, em que $\Delta \mathrm{g}_{\mathrm{j}(\mathrm{I})}$ é o ganho esperado do caráter j, com a seleção baseada no índice I; $\mathrm{DS}_{\mathrm{j}(\mathrm{I})}$ é o diferencial de seleção do caráter j, com a seleção baseada no índice I e $\mathrm{h}_{\mathrm{j}}^{2}$ é a herdabilidade do caráter j.

No índice de seleção com base nos ganhos desejados (Pesek \& Baker, 1969), os coeficientes b são calculados de acordo com a relevância estabelecida pelo melhorista, em sua especificação dos ganhos desejados em cada característica. A construção deste índice envolve o conhecimento da expressão do ganho esperado dos vários caracteres, que é definido por $b=G^{-1} \Delta g_{d}$ sendo $\Delta \mathrm{g}_{\mathrm{d}}$ o vetor de ganhos desejados.

Os pesos econômicos utilizados para o índice de Smith (1936) e Hazel (1943) e os ganhos desejados para o índice de Pesek \& Baker (1969) foram: o coeficiente de variação genética; o coeficiente de variação experimental; o desvio-padrão genético; a razão entre o coeficiente de variação genética e o coeficiente de variação experimental; a herdabilidade; a média; e vários pesos obtidos, aleatoriamente, por tentativas.

Na realização das análises estatísticas, foi utilizado o aplicativo computacional em genética e estatística, denominado programa Genes (Cruz, 1997).

\section{Resultados e Discussão}

O diagnóstico revelou multicolinearidade severa (Tabela 1), segundo critério de Montgomery \& Peck (1981), fato indesejável, pois, nesses níveis, a multicolinearidade pode provocar resultados inadequados nas análises de dados (Cruz \& Carneiro, 2003).

Aplicou-se a técnica de análise de fatores nos experimentos de Marilândia e de Sooretama. Nos dois locais, foram considerados, nas análises, valores mínimos de 0,70 para cargas fatoriais finais (CFF) e comunalidade (COM).

No experimento em Marilândia, foram obtidos quatro fatores. O primeiro fator (F1) relacionou-se com a característica grãos retidos em peneiras (Pen.), Pen.17 (CFF: -0,8186; COM: 0,7641), Pen.15 (CFF: -0,8926; COM: 0,8237), Pen.13 (CFF: 0,8985; COM: 0,8593), Pen.11 (CFF: 0,8777; COM: 0,8752) e PM (CFF: -0,9619; COM: 0,9752). Este fator foi interpreta- 
do como complexo denominado Peneira. O segundo fator (F2) relacionou-se com a característica ciclo (CFF: 0,7959; COM: 0,7659), CeCo (CFF: 0,8791; COM: 0,8337), CeBe (CFF: 0,9294; COM: 0,9123), CoBe (CFF: 0,7189; COM: 0,8757), e foi o mais influenciado por beneficiamento e ciclo, o que justifica o complexo denominado Rendimento 1 . O terceiro fator (F3) foi o mais associado com a qualidade do tipo de grão, relacionou-se com as características chato (CFF: 0,9469; COM: 0,9599) e moca (CFF: -0,9559; COM: 0,9609), o que justifica o complexo denominado Tipo de grão. O quarto fator (F4) foi relacionado com frutos chochos (CFF: 0,8861; COM: 0,8005), e justifica o complexo designado Chocho. As características de produção em kg ha-1 de grãos beneficiados, com $14 \%$ de umidade e porcentual de umidade não foram justificadas por nenhum complexo, pois alcançaram valores inferiores ao mínimo estipulado para CFF e COM.

No experimento em Sooretama, foram obtidos três fatores. O primeiro fator (F1) relacionou-se com a característica tamanho dos grãos. Este fator explica o complexo denominado Peneira, como em Marilândia: com Pen.17 (CFF: 0,8970; COM: 0,8393), Pen.15 (CFF: 0,9550; COM: 0,9212), Pen.13 (CFF: -0,8577; COM: 0,7381), Pen.11 (CFF: -0,8534; COM: 0,7880) e PM(CFF: 0,9688; COM: 0,9704). O segundo fator (F2) foi mais relacionado com rendimento, associado com as características $\mathrm{CeBe}$ (CFF: 0,9287; COM: 0,9330), CoBe (CFF: 0,9237; COM: 0,9231) e chocho (CFF: 0,8168; COM: 0,7479), este fator explica o complexo denominado Rendimento 2. $\mathrm{O}$ terceiro fator (F3) foi mais influenciado pela qualidade e relacionou-se com as características chato (CFF: -0,9415; COM: 0,9538) e moca (CFF: -0,9415; COM: 0,9538), que explica o complexo Tipo de grão. Não foi obtido um quarto fator (F4) neste experimento. As características: ciclo - número de dias do florescimento principal à colheita; produção de grãos, em $\mathrm{kg} \mathrm{ha}^{-1}$ de grãos beneficiados, com $14 \%$ de umidade; relação em quilograma de café cereja/café coco; e porcentual de umidade não foram explicadas por nenhum complexo, pois não atingiram os valores mínimos estabelecidos para CFF e COM.

A adoção preliminar da técnica de análise de fatores, visando à simplificação estrutural no número de caracteres disponíveis, sem perda de interpretação biológica, permitiu também solucionar o problema de multicolinearidade, que invalidava a aplicação da teoria de índice de seleção ou impedia que os coeficientes estimados mostrassem confiabilidade para uso prático, em seleção simultânea de caracteres. Uma nova análise de multicolinearidade, com número reduzido de variáveis, que incluía apenas fatores estimados e características que não eram explicadas pelos fatores, demonstrou que a matriz de correlação possuía nível fraco de multicolinearidade, sendo, portanto, aceitável o seu uso no processo de estimação dos índices de seleção.

Os índices de seleção de Smith (1936) e Hazel (1943) e Pesek \& Beker (1969) foram estabelecidos a partir da combinação linear da característica produção de grãos, nos dois locais, e nos complexos definidos na análise de fatores Peneira (F1), Rendimento 1 (F2), Tipo de grão (F3) e Chocho (F4), em Marilândia, e nos complexos Peneira (F1), Rendimento 2 (F2) e Tipo de grão (F3), em Sooretama.

Nos programas de melhoramento de café, ganhos em algumas características que proporcionem aumento das médias, como a produção de grãos, são desejáveis. Mas, em outras características, busca-se a redução de suas médias, como porcentagem de grãos moca, que é indesejável, pois reduz o rendimento do material e deprecia seu valor comercial (Antunes Filho \& Carvalho, 1954; Carvalho \& Antunes Filho, 1955). A seleção deve ser coerente com os objetivos desejados e o processo de seleção empregado, de modo que resulte em melhores ganhos simultâneos.

A seleção direta e indireta, nas características originais, não proporcionou ganhos simultâneos adequados (Tabela 2)

Tabela 1. Diagnóstico de multicolinearidade, nos ensaios com 14 características (completo) e nos ensaios depois da aplicação de análise de fatores nos complexos, em Marilândia e Sooretama(1).

\begin{tabular}{|c|c|c|c|c|c|}
\hline Ensaio & $r \geq 0,80$ & $\mathrm{VIF} \geq 0,80$ & $\mathrm{NC}\left(\lambda_{\text {máx }} / \lambda_{\min }\right)$ & Determinante da matriz & Multicolinearidade \\
\hline & & & Marilândia & & \\
\hline Completo & 8 & 9 & $42.148,774979$ & 0,00 & Severa \\
\hline Fatores & 0 & 0 & 12,712851 & 0,114963 & Fraca \\
\hline & & & Sooretama & & \\
\hline Completo & 7 & 9 & $13.291,799874$ & 0,00 & Severa \\
\hline Fatores & 0 & 0 & 11,614637 & 0,114403 & Fraca \\
\hline
\end{tabular}

(1)Coeficiente de correlação; VIF: fator de inflação da variância; NC: número de condições da matriz de correlação, em que NC $\leq 100$ : multicolinearidade fraca; $100<\mathrm{NC}<1.000$ : multicolinearidade moderada a forte; e NC $\geq 1.000$ : multicolinearidade severa. 





em nenhuma das características. Obtiveram-se ganhos indiretos muito inferiores, em relação aos valores ideais, que são os ganhos por seleção direta de cada característica. A seleção direta em produção, por exemplo, proporciona um ganho indireto para Pen.17 de 27,81\%, em Marilândia, e de 5,25\% (decréscimo) em Sooretama, mantendo-se abaixo do ganho predito como ideal, que seria de 121,55\%, em Marilândia, e de 130,36\% em Sooretama. A seleção direta nos complexos fatoriais permitiu ganhos adequados nas características que eram explicadas pelos complexos e ganhos que foram próximos dos ganhos preditos por seleção direta nas características, como, por exemplo, para moca, que, em Marilândia, teve um ganho predito por seleção direta de $24 \%$ (decréscimo), e na seleção direta no complexo, de 22,59\% (decréscimo). Em Sooretama, o ganho predito por seleção direta foi de 22,08\% (decréscimo), e por seleção via complexo, de 21,69\% (decréscimo). Embora os ganhos da seleção direta nos complexos fatoriais, nos dois locais, tenham sido adequados nas características explicadas em cada um, os indiretos foram inadequados, como pode ser verificado quanto à produção e grãos retidos em peneiras, sem ganhos indiretos adequados via seleção por complexo, em nenhum dos dois locais (Tabela 2). Esses resultados não foram adequados, já que, de acordo com Ferrão et al. (1999) e Fonseca (1999), busca-se um ideótipo de C. canephora, cujo desempenho abranja, além de outras características, alta produção e aumento de peneira. Em virtude de os resultados não terem sido adequados para a seleção simultânea, utilizaram-se os índices de seleção de Smith (1936) e Hazel (1943) e de Pesek \& Baker (1969), nos complexos fatoriais e produção, para se alcançar ganhos simultâneos adequados nas características aumento de grãos tipo chato (Antunes Filho \& Carvalho, 1954), diminuição de grãos chochos (Mônaco, 1960) e redução das relações de beneficiamento cereja/coco, cereja/beneficiado, coco/beneficiado.

Nos dois índices de seleção, Smith (1936) e Hazel (1943) e Pesek \& Baker (1969), quando foram atribuídos valores arbitrários a pesos econômicos e ganhos desejados, ou de forma interativa, tutorados pelas magnitudes e sentidos dos ganhos, nos vários caracteres fornecidos pelo aplicativo computacional, foram obtidos os melhores ganhos preditos, nos dois locais.

Em Marilândia, embora o índice de Smith (1936) e Hazel (1943), não tenha alcançado ganhos tão próximos da seleção direta, a seleção via complexo resultou em ganhos em sentidos e magnitudes adequados para todas as 14 características envolvidas. O índice de Pesek \& Beker (1969), não foi tão eficiente quanto o índice clássico, tendo alcançado um ganho predito como baixo para produção e grãos retidos em peneiras, mesmo quando foram utilizados como ganhos desejados os valores obtidos por tentativas.

Em Sooretama, apesar de o índice de Pesek \& Baker (1969) ter predito um ganho de seleção alto para produção, não aconteceu o mesmo para as características grãos retidos em peneiras, o que resultou em ganhos muito pequenos e ganhos biológicos inadequados em CeCo e ciclo, com magnitudes contrárias às desejadas em café. O índice clássico, como em Marilândia, forneceu melhor predição de ganhos por seleção que o de Pesek \& Baker (1969). Granate et al. (2002), ao trabalhar com 166 famílias de meios-irmãos de milho pipoca, também conseguiram ganhos preditos superiores com o índice de seleção de Smith (1936) e Hazel (1943).

\section{Conclusões}

1. Os ganhos preditos com o índice de seleção de Smith e Hazel são superiores ao índice de Pesek \& Beker.

2. O índice de seleção de Smith e Hazel, quando utilizado para a seleção simultânea via complexos e produção nos dois locais, com os pesos obtidos por tentativas, permite estimar os ganhos preditos mais adequados, em todas as características, de acordo com o interesse para o melhoramento de C. canephora.

3. A utilização de índices de seleção, via complexos fatoriais, em programas de melhoramento de C. canephora var. Conilon é adequada e permite a predição de ganhos simultâneos adequados em todas as características.

\section{Agradecimentos}

Ao Instituto Capixaba de Pesquisa, Assistência Técnica e Extensão Rural (Incaper), pela permissão para a utilização de dados de seu programa de melhoramento genético de ‘Conilon'; à Universidade Federal de Viçosa, ao CNPq e à Capes, pelo suporte.

\section{Referências}

ANTUNES FILHO, H.; CARVALHO, A. Melhoramento do cafeeiro. VII. Ocorrência de lojas vazias em frutos de café "Mundo Novo". Bragantia, v.13, p.65-179, 1954. 
CARVALHO, A.; ANTUNES FILHO, H. Melhoramento do cafeeiro. Bragantia, v.14, p.62-81, 1955.

CARVALHO, S.P. Métodos alternativos de estimação de coeficientes de trilha $e$ índices de seleção, sob multicolinearidade. 1995. 163p. Tese (Doutorado) - Universidade Federal de Viçosa, Viçosa.

CHARRIER, A.; BERTHAUD, J. Principles and methods in coffee plant breeding: Coffea canephora Pierre. In: CLARK, R.J.; MACRAE, R. (Ed.). Coffee agronomy. London: Elsevier, 1988. p.167-195.

CRUZ, C.D. Programa GENES: aplicativo computacional em genética e estatística. Viçosa: UFV, 1997. 442p.

CRUZ, C.D.; CARNEIRO, P.C. Modelos biométricos: VII. 1.ed. rev. Viçosa: UFV, 2003. 623p.

CRUZ, C.D.; REGAZZI, A.J. Modelos biométricos aplicados ao melhoramento genético. 2.ed. rev. Viçosa: UFV, 2001. 390p.

FERRÃO, R.G.; FONSECA, A.F.A.; FERRÃO, M.A.G. Programa de melhoramento genético de café robusta no Brasil. In: SIMPÓSIO DE ATUALIZAÇÃO EM GENÉTICA E MELHORAMENTO DE PLANTAS: GENÉTICA E MELHORAMENTO DO CAFEEIRO, 3., 1999, Lavras. Anais. Lavras: UFLA, Núcleo de Estudos em Cafeicultura, 1999. p.50-65.
FONSECA, A.F.A. Análises biométricas em café Conilon (Coffea canephora Pierre). 1999. 121p. Tese (Doutorado) - Universidade Federal de Viçosa, Viçosa.

GRANATE, M.J.; CRUZ, C.D.; PACHECO, C.A.P. Predição de ganho genético com diferentes índices de seleção no milho pipoca CMS-43. Pesquisa Agropecuária Brasileira, v.37, p.1001-1008, 2002.

HAZEL, L.N.; LUSH, J.L. The genetic basis for constructing selection indexes. Genetics, v.39, p.476-490, 1943.

MATIELLO, J.B.; ALMEIDA, S.R. Variedades de café: como escolher, como plantar. Rio de Janeiro: MAA: SDR: PROCAFÉ: PNFC, 1997. 64p.

MÔNACO, L.C. Melhoramento do cafeeiro: XVII. Seleção do café maragogipe. Bragantia, v.19, p.459-492, 1960.

MONTGOMERY, D.C.; PECK, E.A. Introduction to linear regression analysis. New Work: J. Wiley \& Sons, 1981. 504p.

PESEK, J.; BAKER, R.J. Desired improvement in relation to selected indices. Canadian Journal of Plant Science, v.49, p.803-804, 1969.

SMITH, H.F. A discriminant function for plant selection. Annals of Eugenics, v.7, p.240-250, 1936.

Recebido em 9 de setembro de 2004 e aprovado em 5 de maio de 2005 